\title{
COUPLING OF A KERS POWERTRAIN AND A 4 LITRE GASOLINE ENGINE FOR IMPROVED FUEL ECONOMY IN A FULL SIZE CAR
}

\author{
Alberto A. Boretti \\ School of Science and Engineering, University of Ballarat, Ballarat, VIC, Australia
}

Copyright $@ 2010$ SAE International

\begin{abstract}
Improvements of vehicle fuel economy are being considered using a mechanically driven flywheel to reduce the amount of mechanical energy produced by the thermal engine recovering the vehicle kinetic energy during braking. A mechanical system having an overall efficiency over a full regenerative cycle of about $70 \%$, about twice the efficiency of battery-based hybrids, is coupled to a naturally aspirated gasoline engine powering a full size sedan. Results of chassis dynamometer experiments and engine and vehicle simulations are used to evaluate the fuel benefits introducing a kinetic energy recovery system and downsizing of the engine. Preliminary results running the new European driving cycle (NEDC) show KERS may reduce fuel consumption by $25 \%$ without downsizing, and $33 \%$ with downsizing of the 4 litre engine to 3.3 litres.
\end{abstract}

\section{INTRODUCTION}

Regenerative braking is probably the best option to improve the fuel economy of passenger cars, light and heavy duty trucks and busses covering driving cycles characterized by frequent accelerations and decelerations [1-16]. Recovering the kinetic energy otherwise lost during braking may indeed significantly reduce the amount of energy to be supplied by the engine to reaccelerate the vehicle.

Today most efficient passenger cars are Hybrid Electric Vehicles (HEV) [17] exploiting the benefits of recovering braking energy. These cars couple thermal engine, electric motor, generator, battery pack, drive wheels and brakes to power the vehicle with modulated thermal and electric motors. However, the increase in vehicle weight and dimensions per load volume as well as the inefficiency of the multiple mechanical to electric energy conversions make their effectiveness much less than what is expected by a car much more environmentally expensive to produce, maintain and dispose, leaving scope for developing a better non electric alternative.

Fuel economy and emission compliance is measured over test cycles. The ECE+EUDC cycle is a test cycle performed on a chassis dynamometer used for emission certification of light duty vehicles in Europe [EEC Directive 90/C81/01]. The entire cycle includes four ECE segments, repeated without interruption, followed by one EUDC segment. Before the test, the vehicle is allowed to soak for at least 6 hours at a test temperature of $20-30^{\circ} \mathrm{C}$. It is then started and the emission sampling begins at the same time. This cold-start procedure is also referred to as the New European Driving Cycle (NEDC).

The ECE cycle is an urban driving cycle, also known as UDC. It was devised to represent city driving conditions, e.g. in Paris or Rome. It is characterized by low vehicle speed, low engine load, and low exhaust gas temperature. The EUDC (Extra Urban Driving Cycle) segment has been added after the fourth ECE cycle to account for more aggressive, high speed driving modes. The maximum speed of the EUDC cycle is $120 \mathrm{~km} / \mathrm{h}$.

Table 1 summarizes the main parameters for both the ECE and EUDC cycles, while Figure 1 presents the prescribed velocity of the car. Regenerative braking may be effective in recovering part of the kinetic energy of the decelerating vehicle therefore reducing the amount of energy to be supplied in the following acceleration. The thermal engine has to supply through a fuel conversion process the energy needed for acceleration and cruising of the vehicle. Without regenerative braking, the vehicle kinetic energy is completely dissipated to reduce the vehicle speed. With regenerative braking, part of the kinetic energy of the vehicle can be stored and used to reduce the energy supply by the thermal engine to reaccelerate the vehicle. 


\begin{tabular}{||l|r|r||}
\hline Characteristics & ECE & EUDC \\
\hline Distance $[\mathrm{km}]$ & $4 \times 1.013=4.052$ & 6.955 \\
\hline Duration $[\mathrm{s}]$ & $4 \times 195=780$ & 400 \\
\hline Average Speed $[\mathrm{km} / \mathrm{h}]$ & 18.7 (with idling) & 62.6 \\
\hline Maximum Speed $[\mathrm{km} / \mathrm{h}]$ & 50 & 120 \\
\hline \hline
\end{tabular}

Table 1 - Main characteristics of ECE and EUDC sectors.

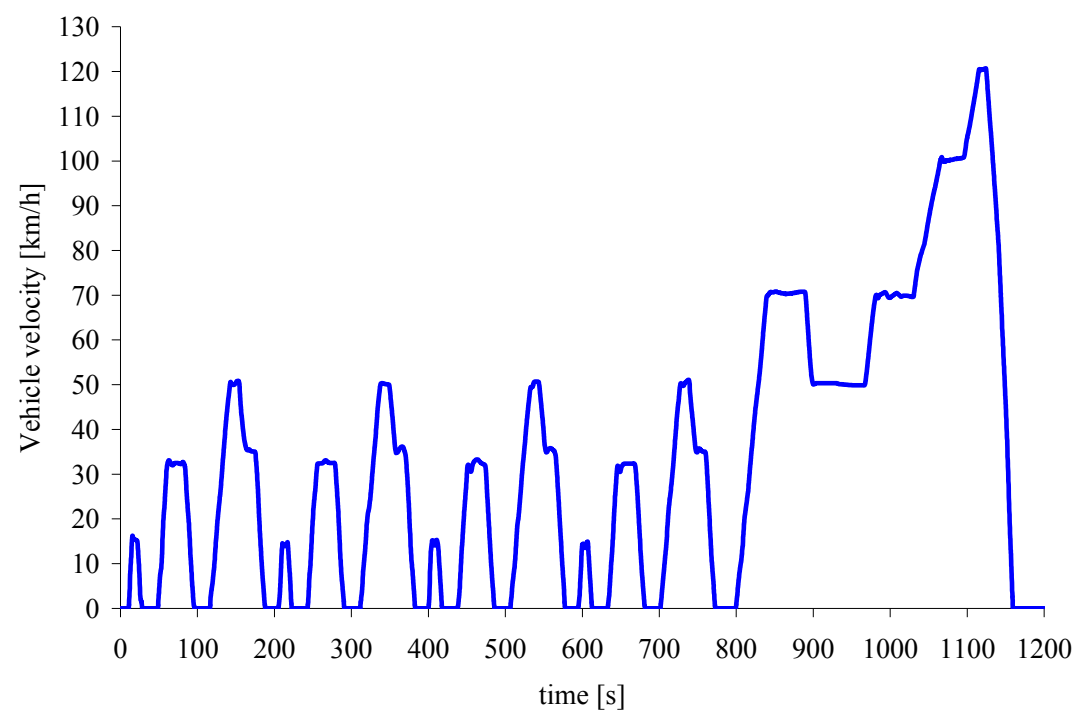

Figure 1 - Vehicle velocity over the NEDC.

It is a fundamental of physics that transforming energy from one form to another inevitably introduces significant losses. This explains why the efficiency of battery-based hybrids is so low for a regenerative braking cycle. When a battery is involved, there are four efficiency reducing transformations in each regenerative braking cycle. (1) Kinetic energy is transformed into electrical energy in a motor/generator, (2) electrical energy is transformed into chemical energy as the battery charges up, (3) the battery discharges transforming chemical into electrical energy, (4) the electrical energy passes into the motor/generator acting as a motor and is transformed once more into kinetic energy. These four energy transformations reduce the overall level of efficiency. If the motor/generator operates at $80 \%$ efficiency under peak load, in and out, and the battery charges and discharges at $75 \%$ efficiency at high power, the overall efficiency over a full regenerative cycle is only $36 \%$ [12-14].

The ideal solution is to avoid all four of the efficiency reducing transformations from one form of energy to another by keeping the vehicle's energy in the same form as when the vehicle starts braking when the vehicle is back up to speed. This can be done using high-speed flywheels [12-15], popular in space and uninterruptible power supplies for computer systems, but relatively novel in ground vehicles.

For the space and computer applications, high-speed motor/generators are used to add and remove energy from the flywheels. In ground vehicles, more efficient mechanical, geared systems are preferred. A mechanically driven flywheel system has losses, due to friction in bearings and windage effects, which make it less efficient than a battery-based system in storing energy for long times. Over the much shorter periods required in cut-and-thrust traffic, a mechanically driven flywheel is however much more effective, providing an overall efficiency over a full regenerative cycle of more than $70 \%$, almost twice the value of battery-based hybrids [12$14]$.

Almost every vehicle with a manual transmission is already fitted with a flywheel to smooth the flow of power from the engine and to provide a small store of energy to help prevent stalling on launch. Toy cars use a small flywheel geared up to spin fast enough to provide spectacular scale performance. The geared high-speed flywheel concept may now be applied to full-sized cars, trucks and buses, with a resulting dramatic improvement in fuel economy at lower cost and without sacrificing acceleration.

The paper provides an evaluation of KERS benefits through experiments with conventional power trains and simulations with conventional and mechanical hybrid power trains. The improvements in fuel efficiency are computed over a driving cycle recovering the braking energy with the mechanically driven flywheel enabling shut-off of the thermal engine at idle, during braking and during accelerations when energy is available in the flywheel. This reduces the supply of fuel energy to power the vehicle, and ultimately the fuel consumption. 


\section{KINETIC ENERGY RECOVERY SYSTEMS (KERS)}

The vehicle fuel economy can be dramatically improved by reducing the amount of mechanical energy to be provided by the thermal engine recovering the braking energy. Considering the theoretical advantages of storing the braking mechanical energy with a much more efficient, simple and lighter mechanical device than an electric hybrid power train, and the recent improvements in kinetic energy recovery systems (KERS) for F1 applications [12-14], improvements in fuel economy are being considered using a KERS to recover the braking energy.

For a traditional power train, the driveline equation balances the vehicle side output torque from clutch or torque converter with the inertia torque of the entire driveline and vehicle and the effective torque of the retarding forces on the vehicle, namely aerodynamic, rolling resistance and grade forces:

$$
\begin{aligned}
& \tau_{d v v, v}=\left[I_{\text {trans }}+\frac{I_{\text {trans2 }}}{R_{t}^{2}}+\frac{I_{d s h}}{R_{t}^{2}}+\frac{I_{a x l}}{R_{d}^{2} R_{t}^{2}}+\frac{M_{\text {veh }} r_{\text {whl }}^{2}}{R_{d}^{2} R_{t}^{2}}\right] \frac{d \omega_{d v v}}{d t} \\
- & {\left[\frac{I_{\text {trans } 2}}{R_{t}^{3}}+\frac{I_{d s h}}{R_{t}^{3}}+\frac{I_{a x l}}{R_{d}^{2} R_{t}^{3}}+\frac{M_{v e h} r_{w h l}^{2}}{R_{d}^{2} R_{t}^{3}}\right] \omega_{d v v} \frac{d R_{t}}{d t} } \\
+ & {\left[\frac{F_{a e r}+F_{r o l}+F_{g r d}}{R_{d} R_{t}}\right] r_{w h l} }
\end{aligned}
$$

In the previous equation, $\tau_{d r v, e}$ is the engine side torque of clutch or torque converter, $\tau_{d r v, v}$ the vehicle side torque of clutch or torque converter. $\omega_{d r v}$ the driveline speed on vehicle side of clutch or torque converter, $\mathrm{I}_{a x l}$ the axle moment of inertia, $\mathbf{I}_{d s h}$ the driveshaft inertia, $\mathbf{I}_{\text {trans1 } 1}$ the input side transmission moment of inertia, $\mathbf{I}_{\text {trans } 2}$ the output side transmission moment of inertia, $\mathbf{M}_{v e h}$ the vehicle mass, $\mathbf{r}_{w h l}$ the wheel radius, $\mathbf{F}_{\boldsymbol{a} \text { er }}$ the aerodynamic force on vehicle, $\mathbf{F}_{\text {rol }}$ the rolling resistance force on vehicle, $\mathbf{F}_{\text {grd }}$ the grade force on vehicle, $\mathbf{R}_{\boldsymbol{t}}$ the transmission ratio, $\mathbf{R}_{\boldsymbol{d}}$ the final drive ratio, $\mathbf{t}$ the time. This equation and the engine equation of motion, the latter balancing the engine brake torque with the engine inertia torque and the engine side load torque from the clutch or torque converter, control the operating points (torque and speed) of the engine.

Braking at the wheels may be assimilated to a torque component in the previous equation. Braking at the wheels dissipates the kinetic energy of the vehicle that is therefore completely lost. Conversely, KERS may store the kinetic energy of the vehicle under braking and return it under acceleration. The system utilises a flywheel as the energy storage device and a Continuously Variable Transmission (CVT) to transfer energy to and from the driveline to the rotating flywheel. The transfer of the vehicle kinetic energy to the flywheel kinetic energy reduces the speed of the vehicle and increases the speed of the flywheel. The transfer of the flywheel kinetic energy to the vehicle kinetic energy reduces the speed of the flywheel and increases the speed of the vehicle. The CVT is used because the ratios of vehicle and flywheel speed are different during a braking or an acceleration event. A clutch allows the disengagement of the flywheel when it is not used.

The kinetic energy of the flywheel is $\mathbf{E}=1 / 2 \cdot \mathbf{J} \cdot \boldsymbol{\omega}^{2}$ where $\mathbf{J}$ is the moment of inertia of the flywheel and $\boldsymbol{\omega}$ the angular velocity. The flywheel has a moment of inertia $\mathbf{J}=1 / 2 \cdot \mathbf{m} \cdot\left(\mathbf{r}_{1}^{2}-\mathbf{r}_{2}^{2}\right)$, where $\mathbf{m}$ is the mass, $\mathbf{r}_{1}$ the outer radius and $\mathbf{r}_{2}$ the inner radius. It is possible to use low speed high inertia flywheels, or high speed low inertia flywheels, to store same energy. F1 systems use a very light weight composite flywheel, made up of a carbon fibre filament wound rim surrounding a steel hub, rotating at very high speed in a vacuum [12-14]. This design has proved to be quite effective but also quite expensive to produce, with other solutions being considered for mass production. The dynamic behaviour of a rigid flywheel rotor in bearings on elastic supports (elastic to account for finite stiffness of bearings, shaft and structures), allows two modes of operation, sub-critical with flywheel speed ranging from zero to a speed that is safely below the first critical speed, and super-critical with flywheel speed ranging between two consecutive critical speeds. The first mode of operation permits low energy storage, the second mode high energy storage. This latter is the preferred mode for compact and light applications. Therefore, wheel braking is partially replaced by increasing the flywheel speed of rotation from the low to the high value, consequently storing part of the available kinetic energy. This stored kinetic energy is then used to reaccelerate the vehicle reducing the flywheel speed of rotation from the high to the low value.

The system efficiency is the key area where the mechanical hybrid system excels over the electric hybrid. Battery based electric hybrid systems require a number of energy conversions each with corresponding efficiency losses. On reapplication of the energy to the drive line, the global energy conversion efficiency is $31-34 \%$. The mechanical hybrid system storing energy mechanically in a rotating fly wheel eliminates the various energy conversions and provides a global energy conversion efficiency exceeding $70 \%$ [1214], more than twice the efficiency of an electric system. However, KERS may store energy efficiently only over a small time interval. Therefore, more complex buffering strategies where the thermal engine operation is virtually decoupled by the road load that are possible with electric hybrid vehicles are not possible with mechanical hybrid vehicles.

Recovery of the braking energy reduces the amount of thermal energy requested to power the vehicle and reduce the time the thermal engine is running. Efficiency of KERS energy storage and release, maximum amount of energy being stored, energy loss in start/stop of engine and timing of deceleration and acceleration processes and therefore efficiency of the control all play a dominant role in 
determining the best configuration of a KERS assisted power train. Using optimized strategies, $\mathrm{CO}_{2}$ and fuel consumption reductions of over $20 \%$ are possible on the NEDC cycle and more than $30 \%$ are possible in real world conditions [12-14].

The $60 \mathrm{~kW}$ maximum power and $400 \mathrm{~kJ}$ energy storage F1 KERS by Flybrid [12-13] has a very light and compact design. It weighs $25 \mathrm{~kg}$ and has a volume of 13 litres. The $240 \mathrm{~mm}$ diameter flywheel weighs $5 \mathrm{~kg}$ and revolves at up to $64,500 \mathrm{rpm}$. A passenger car KERS has been designed following same concept for an energy capacity of $400 \mathrm{~kJ}$ but a maximum power of $30 \mathrm{~kW}$. Weight and dimension are slightly increased to reduce the speed of rotation and account for adoption of a vacuum pump. However, the KERS remain light and compact for easy installation. The efficiency of a round trip regenerative braking is assumed to be 70\% [12-14]. This is a minimum value often exceeded during operation [12-14]. Charging and discharging rates are very fast, $50 \mathrm{~ms}$ zero to full charge and vice versa. Therefore, the KERS is also quite effective in braking. Control of the coupled regenerative and friction braking is very simple. The KERS is charged during a deceleration and then immediately discharged during the subsequent acceleration. The engine is shut-off during decelerations, and it is restarted during the following acceleration when the kinetic energy recovered during the braking is fully consumed. $70 \%$ of the energy needed to brake the vehicle is then used to replace the internal combustion engine supply of energy until fully consumed. Reference values are assumed for energy penalties for start/stop. Results of vehicle simulations are presented in the following section.

\section{NEDC RESULTS FOR A FULL SIZE PASSENGER CAR}

Experiments and simulations have been performed for a large full size, passenger car. The car is powered by a naturally aspirated, 4 litre, stoichiometric gasoline engine. Basic data of engine and vehicle are presented in Tables 2 and 3 . Figure 2 presents the Brake Specific Fuel Consumption (BSFC) vs. Brake Mean Effective Pressure (BMEP) and engine speed. These values have been computed with an engine model (WAVE, [18]) validated vs. steady engine dynamometer test data. Results of vehicle fuel economy over the NEDC have then been obtained with a vehicle model (Lotus Vehicle [19]) interpolating the previous map with instantaneous road load torque and speed validated vs. unsteady vehicle chassis dynamometer test data.

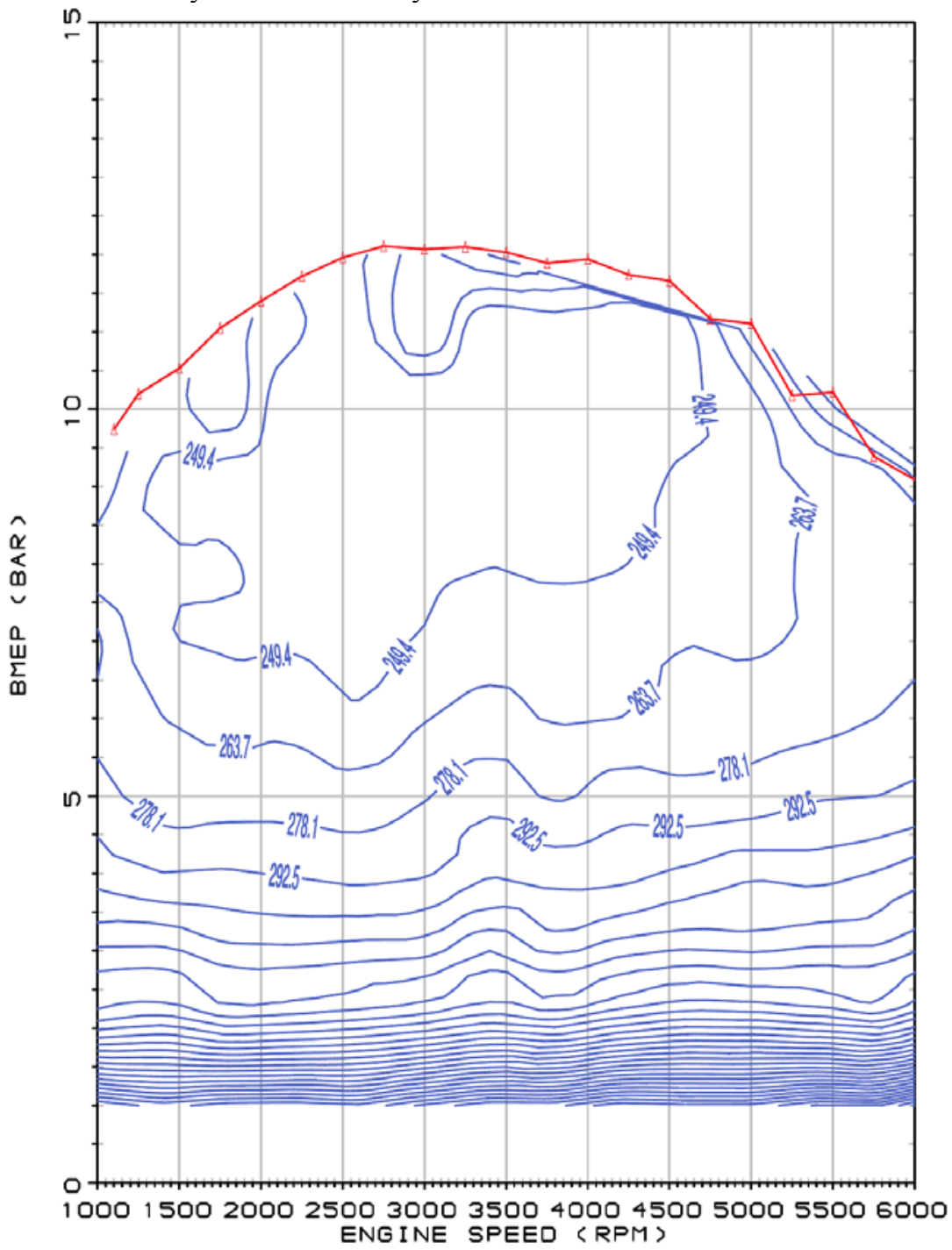

Figure 2 - Brake specific fuel consumption (in $\mathrm{g} / \mathrm{kWh}$ ) map for a 4 litre gasoline engine. 


\begin{tabular}{||c|c|}
\hline \hline Number of Cylinders & 6 \\
\hline Bore [mm] & 92.2 \\
\hline Stroke [mm] & 99.3 \\
\hline Compression ratio & 10.5 \\
\hline Swept Volume [1] & 4 \\
\hline
\end{tabular}

Table 2 - Basic engine data, full size passenger car.

\begin{tabular}{||c|c|}
\hline Weight $[\mathrm{kg}]$ & 1810 \\
\hline Frontal Area $\left[\mathrm{m}^{2}\right]$ & 2.250 \\
\hline Drag Coefficient & 0.298 \\
\hline Tyre Rolling Radius [m] & 0.316 \\
\hline Final Drive Ratio & 2.73 \\
\hline Gearbox & Automatic \\
\hline Number of ratios & 5 \\
\hline Gear. 1 Ratio & 3.22 \\
\hline Gear. 2 Ratio & 2.29 \\
\hline Gear. 3 Ratio & 1.55 \\
\hline Gear. 4 Ratio & 1 \\
\hline Gear. 5 Ratio & 0.75 \\
\hline
\end{tabular}

Table 3 - Basic vehicle data, full size passenger car.

Engine speed, brake mean effective pressure (BMEP) and fuel flow rate during the NEDC are presented in Figures 3 to 5, while Figure 6 presents the operating BMEP vs. engine speed (one point every $0.5 \mathrm{~s}$ ). This figure also presents values of BMEP for wide open throttle (WOT) and minimum brake specific fuel consumption (BSFC) operation.

The engine works far from the minimum specific fuel consumption curve of the engine close to the wide open throttle curve. The baseline configuration with the 4 litre engine requires $0.439 \mathrm{~kg}$ of fuel to cover the $4.052 \mathrm{~km}$ of the urban sector ECE, and $0.850 \mathrm{~kg}$ of fuel to cover the full cycle ECE+EUDC. Considering a density of $0.75 \mathrm{~kg} /$ litre, this corresponds to a fuel economy of 14.4 litres/100 $\mathrm{km}$ over the urban sector, and 10.3 litres $/ 100 \mathrm{~km}$ over the full cycle. The large naturally aspirated engine works the most part of the driving cycle at low speed and BMEP, with low efficiency and high brake specific fuel consumptions, more often around $1500 \mathrm{rpm}$ and 1 bar. The large amount of energy used to accelerate the vehicle is then completely lost decelerating the vehicle.

Considerable improvements for this vehicle may be obtained by introducing smaller, turbocharged diesel or advanced gas engines, because of the larger operational BMEP, the better top efficiency and the better part load efficiency resulting from downsizing, lean operation, higher compression ratio, partial recovery of exhaust energy and throttle-less load control. Considerable improvements may also be obtained recovering the braking kinetic energy with a KERS and therefore stopping the engine during large portions of the cycle when the KERS may provide the energy needed.

Computations have therefore been performed introducing a KERS made up of a high speed flywheel and a CVT. Figure 7 presents the operating BMEP vs. engine speed with the KERS (one point every $0.5 \mathrm{~s}$ ), while figure 8 shows the fuel flow rate computed with and without the KERS. The engine is shut off during a deceleration of the vehicle to stop, and it is restarted during the following acceleration when the kinetic energy recovered during the braking event is fully consumed to re-accelerate the vehicle, run the ancillaries during engine shut-off, and re-start the engine. The efficiency of the charging and discharging process is supposed to be $70 \%$. This means that $70 \%$ of the energy needed to brake the vehicle is then used to replace the internal combustion engine supply of energy until fully consumed. The inevitable differences in the warm-up profile of the engine (engine metal, coolant and oil temperatures vs. time) with and without the KERS are neglected.

These results show the engine may be stopped $50 \%$ of the time with the KERS, with the engine being run roughly $47.5 \%$ of the time to deliver the amount of energy needed by the vehicle during part of the accelerations and cruising, and about $2.5 \%$ to cover the startstop penalties. The configuration with the 4 litre engine and the KERS requires $0.27 \mathrm{~kg}$ of fuel to cover the $4.052 \mathrm{~km}$ of the urban sector ECE, and $0.64 \mathrm{~kg}$ of fuel to cover the full cycle ECE+EUDC. This corresponds to a fuel economy of 8.8 litres/100 km over the urban sector (fuel saving of more than $35 \%$ ), and 7.7 litres/100 km over the full cycle (fuel saving of $25 \%$ ). 


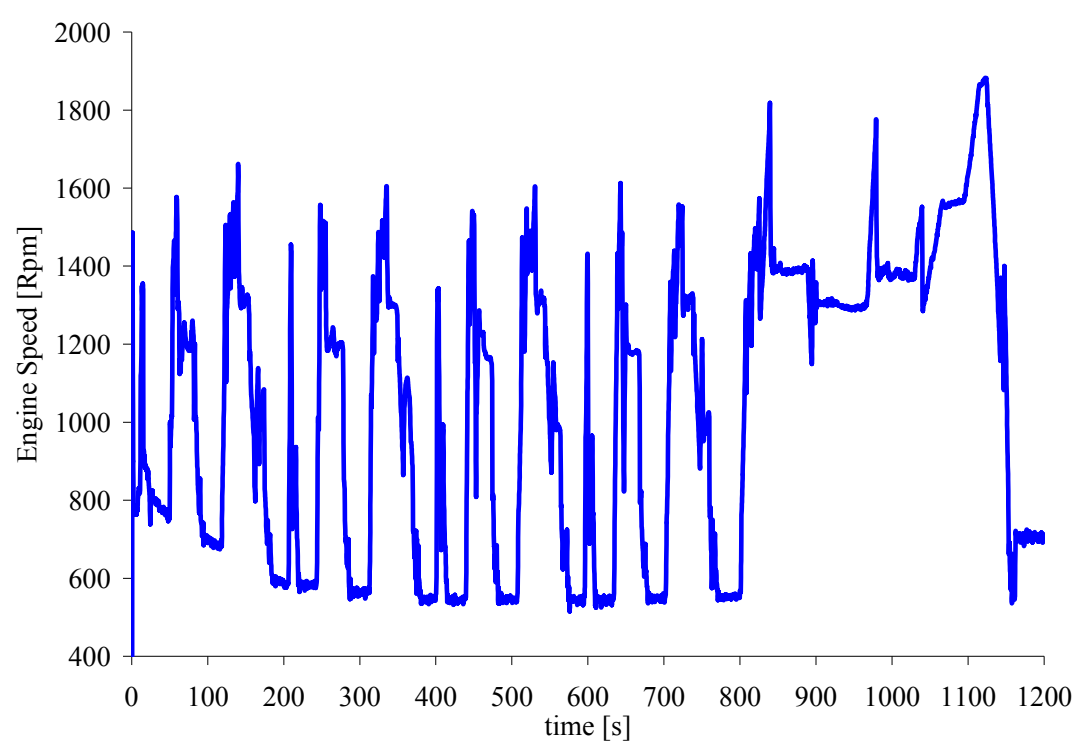

Figure 3 - Engine speed over the NEDC.

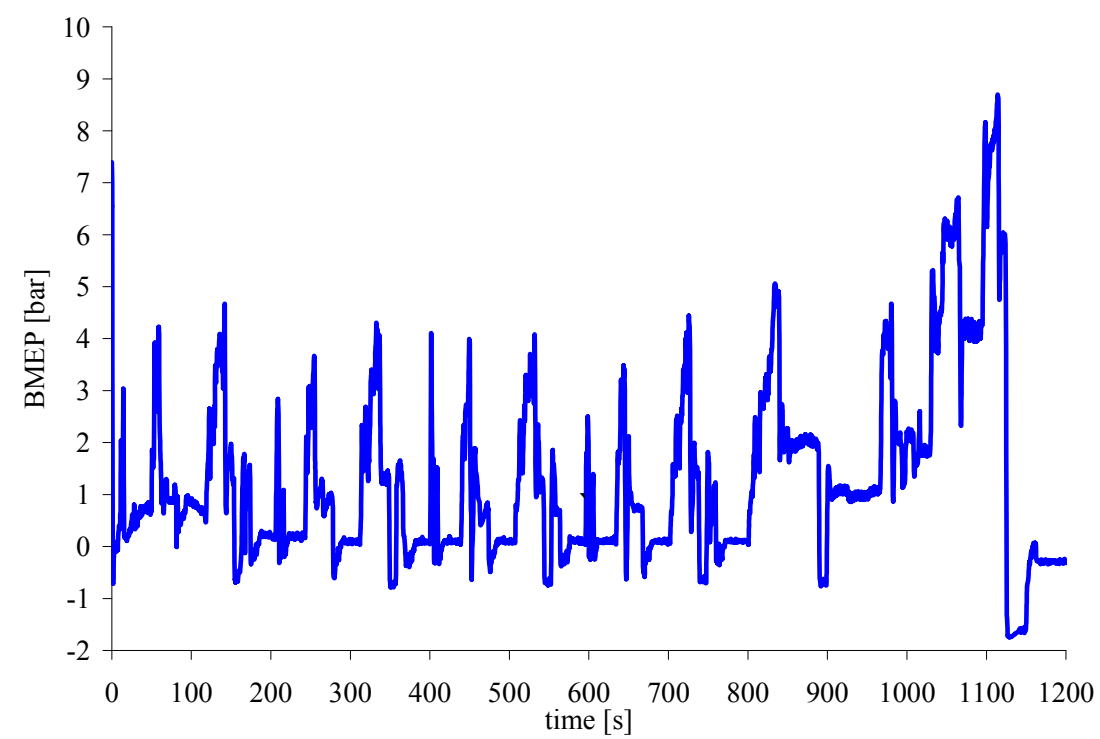

Figure 4 - Engine brake mean effective pressure over the NEDC.

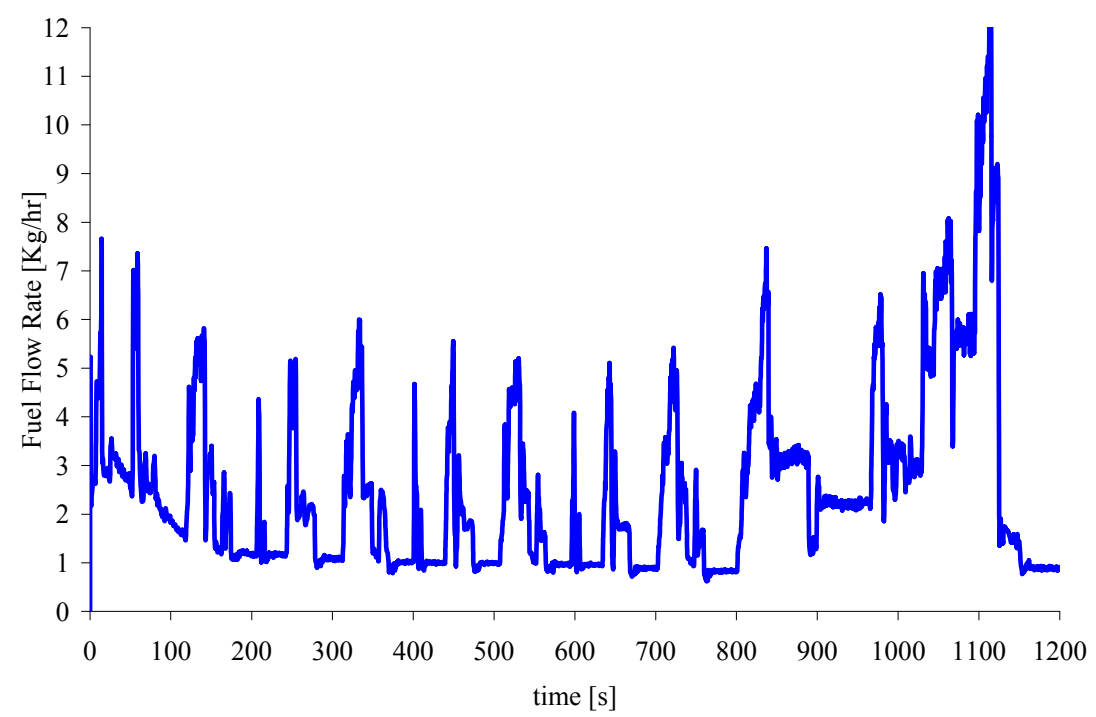

Figure 5 - Engine fuel flow rate over the NEDC. 


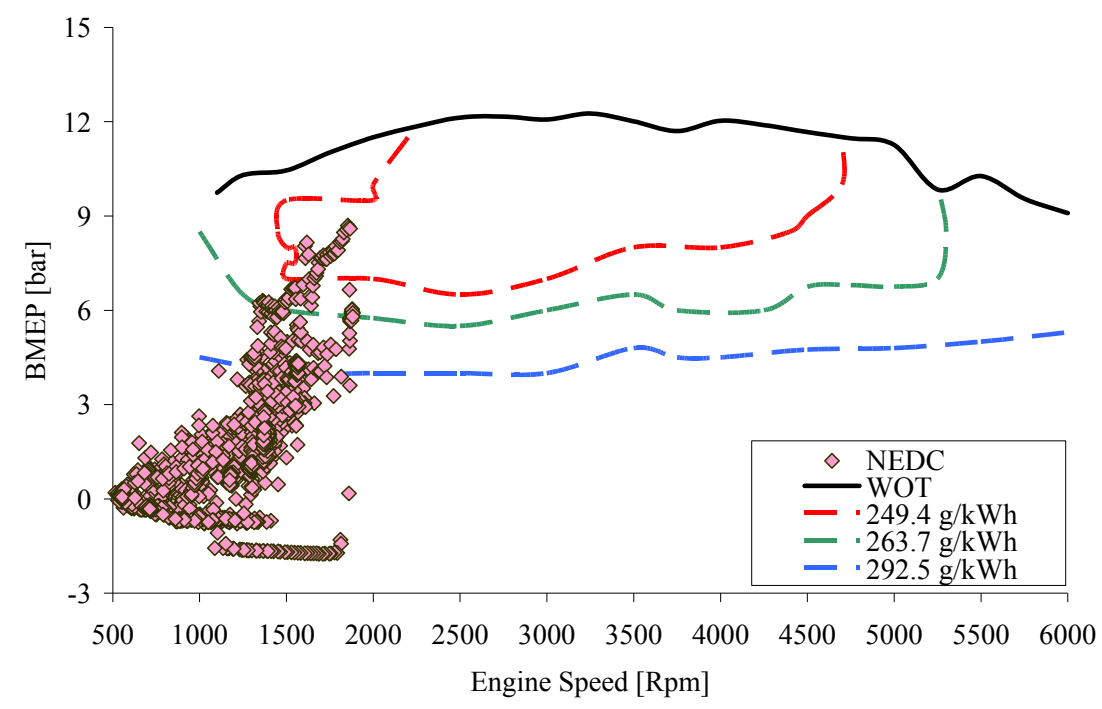

Figure 6 - Engine operating points over the NEDC without KERS.

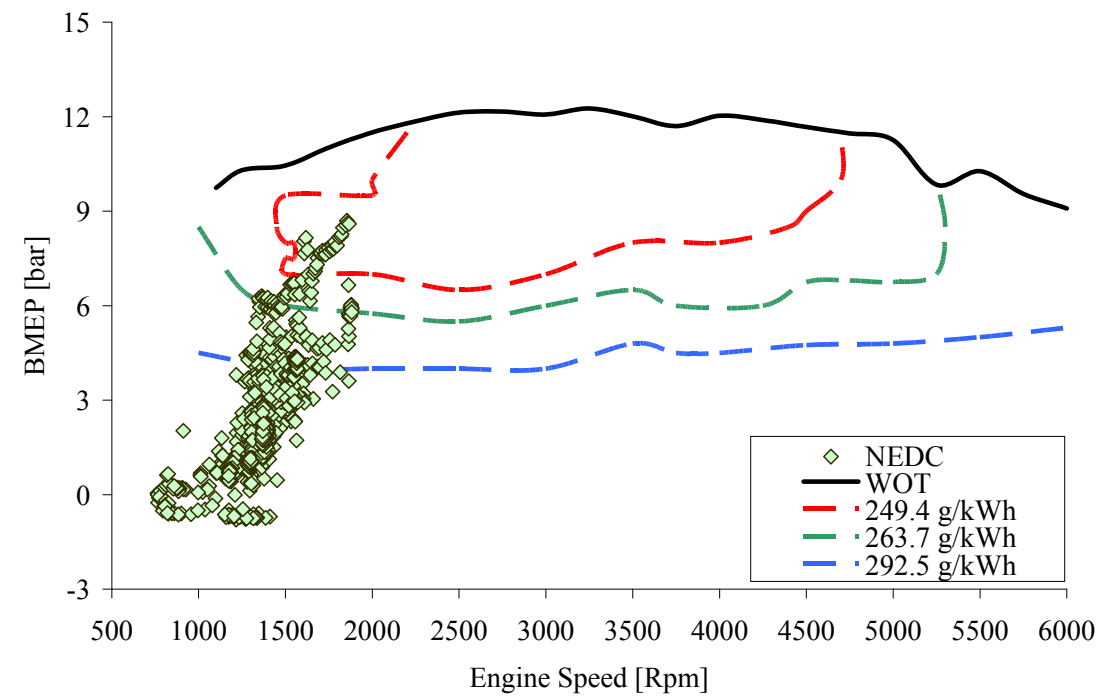

Figure 7 - Engine operating points over the NEDC with KERS.

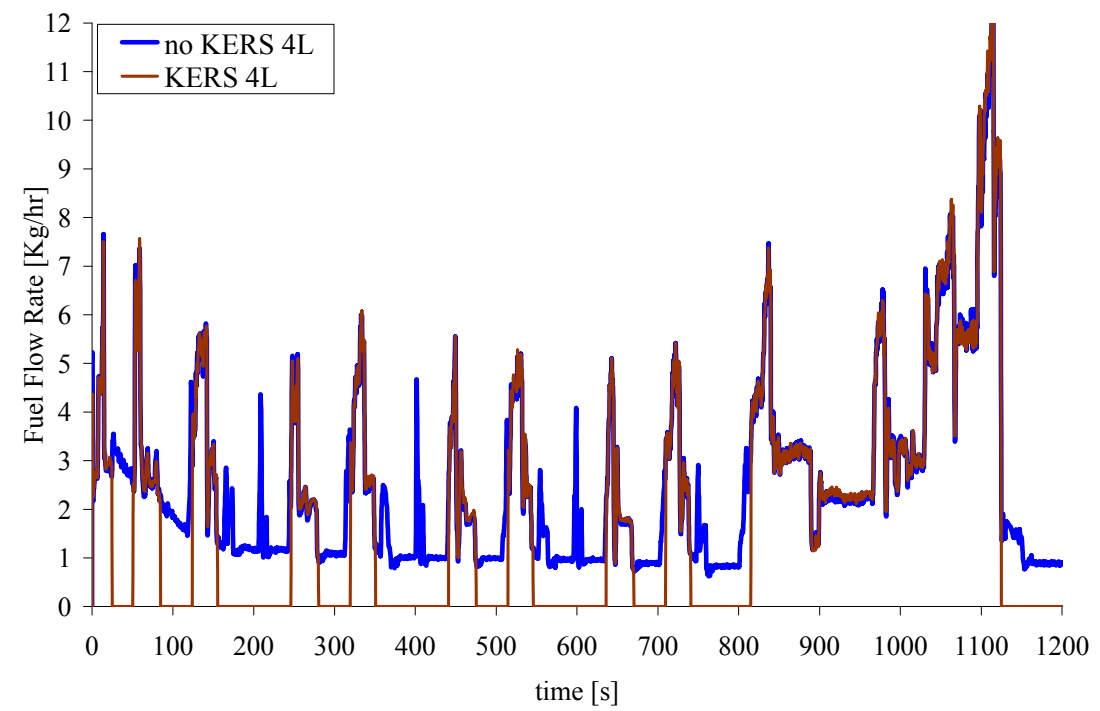

Figure 8 - Engine fuel flow rate over the NEDC with and without KERS. 


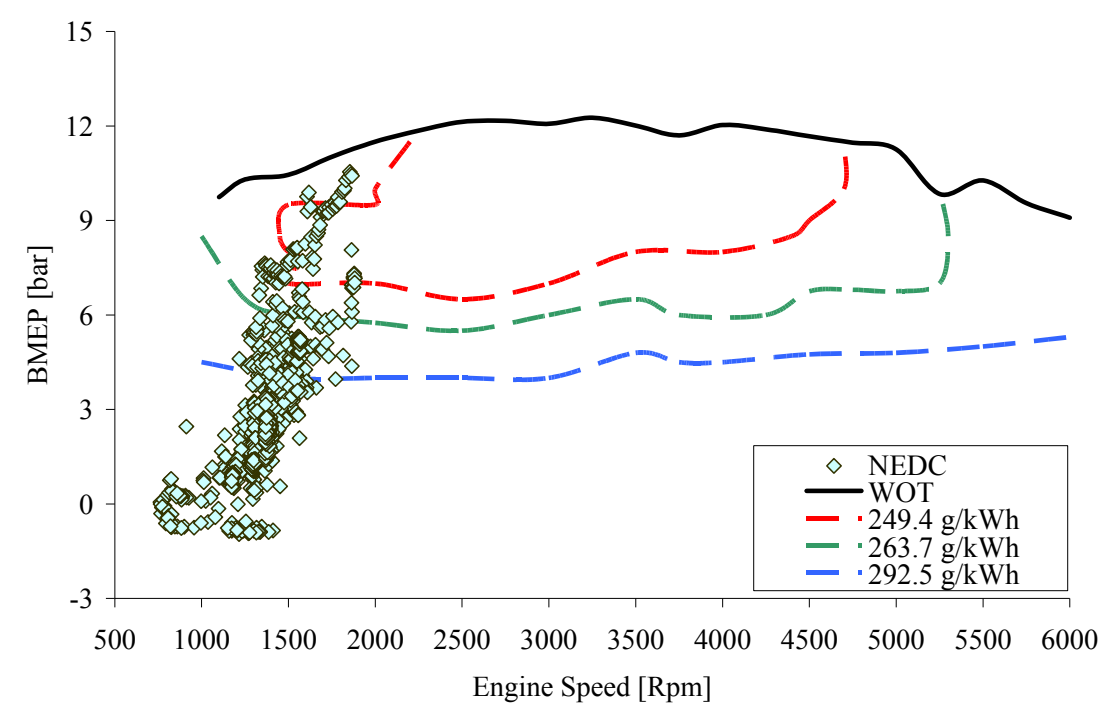

Figure 9 - Engine operating points over the NEDC with KERS and downsizing of the 4 litre engine to 3.3 litres.

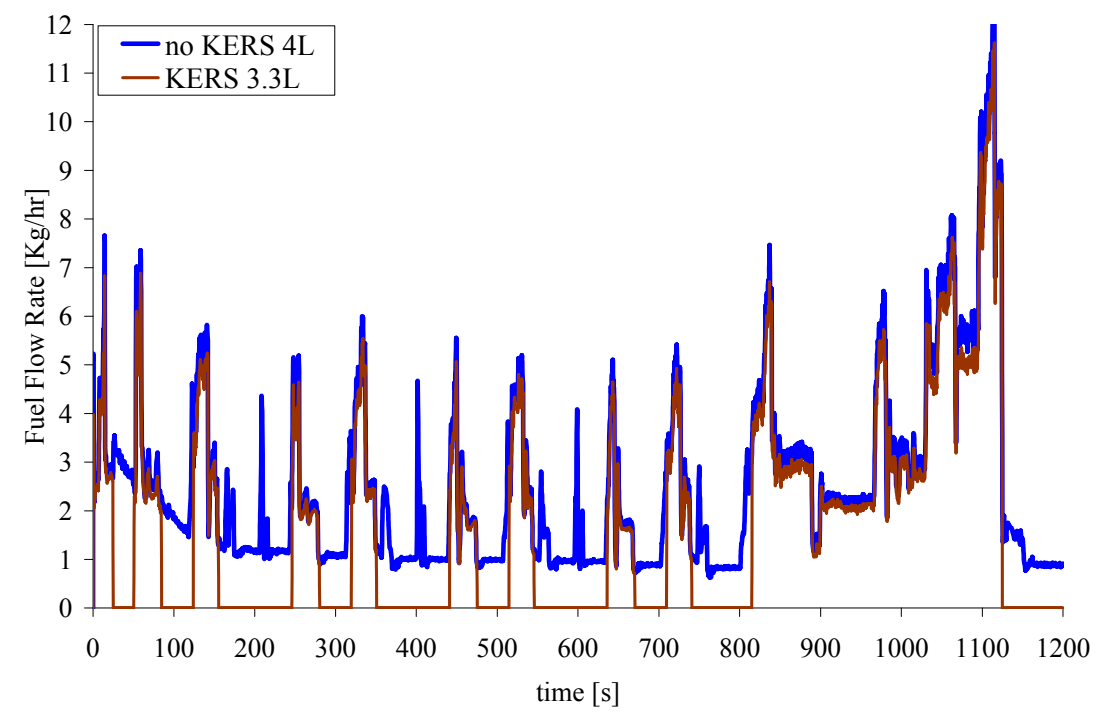

Figure 10 - Engine fuel flow rate over the NEDC without KERS and with KERS and downsizing of the 4 litre engine to 3.3 litres.

It has to be pointed out that the vehicle stops from high speed at the end of the NEDC with immediate engine turn off. This waste all the energy stored in the KERS following the sharp deceleration. Clearly the end of the NEDC cycle is very far from the real life operation of the car, and therefore real life benefits of KERS may be guessed to more than $30 \%$ better fuel economy.

Further improvements may follow downsizing of the internal combustion engine thanks to the boosting provided by the KERS during accelerations. The thermal engine in a conventional car or truck is a compromise having to provide sufficient power during full load strong accelerations, then part load high fuel conversion efficiency when the vehicle is cruising. The displacement needed for full load strong accelerations is a handicap for the cruising part load conversion efficiency. The availability of extra mechanical energy to boost the accelerations may therefore permit downsizing of the thermal engine further improving the fuel economy.

The displacement effect shifts up by a factor equal to the displacement ratio the operating BMEP. In hypothesis the brake specific fuel consumption map is the same for both the original and the downsized engine, reduction of the displacement of the engine from 4 to 3.3 litres produce an improved fuel economy of about 10\% (the resulting brake specific fuel consumptions is $10 \%$ better on average). This is due to the very low part load efficiencies at very low BMEP of the throttle-controlled, stoichiometric, gasoline engine.

Figure 9 presents the operating BMEP vs. engine speed with the KERS also downsizing the engine to 3.3 litres (one point every 0.5 s), while figure 10 shows the fuel flow rate computed without the KERS and with the KERS also downsizing the engine to 3.3 litres. The configuration with the 3.3 litres downsized engine and the KERS reduces the fuel usage to 7 litres per $100 \mathrm{~km}$, with a total fuel saving of $33 \%$. 


\section{DISCUSSION}

Adoption of a KERS may permit regenerative braking, engine buffering and engine downsizing (through torque assistance) as a means of improving efficiency and hence reducing fuel consumption and $\mathrm{CO}_{2}$ emissions. Results presented for a full size passenger car equipped with a 4 litre, in-line six, throttle controlled, port fuel injected, stoichiometric gasoline engine running the new European driving cycle (NEDC) are very promising. The configuration with the 4 litre engine and the KERS reduces the fuel usage of $25 \%$, while the configuration with the 3.3 litres downsized engine and the KERS reduces the fuel usage of 33\%. Table 4 below summarizes the results.

\begin{tabular}{||c|c|c|c|}
\hline ENGINE & 4L & 4L & $3.3 \mathrm{~L}$ \\
\hline KERS & no & yes & yes \\
\hline Fuel consumption [liters/100 km] & 10.3 & 7.7 & 7 \\
\hline Fuel economy improvement [\%] & & +25 & +33 \\
\hline
\end{tabular}

Table 4 - Results of NEDC simulations.

These benefits of a KERS follow the application of a computational tool validated with traditional or hybrid electric power trains but not with a KERS. Prototyping of the KERS and chassis dynamometer testing of the vehicle modified with the KERS is necessary to fully assess the benefits of the technique. Results obtained here are however in line with what has being measured by other researchers in other gasoline applications.

Simulations have only been performed with one vehicle and one driving cycle. Improvements in fuel economy may vary adopting different vehicles, engines and driving cycles. The benefits of the KERS may reduce in passenger cars with smaller, turbo-charged, HSDI Diesel engine, where the efficiency penalty reducing the load by quantity of fuel injected is much smaller than in large throttle controlled gasoline engines.

The end of the NEDC cycle with the stop of the vehicle from high speed and immediate engine turn off is very far from the real life operation of a car. Real life benefits of the KERS in city driving conditions, well represented by the ECE sectors of the NEDC, may therefore be guessed to be at least $30 \%$ better fuel economy on almost every platform, Diesel or gasoline, naturally aspirated or turbo charged, lean burn or stoichiometric, load controlled by throttle or quantity of fuel injected.

\section{CONCLUSIONS}

Flywheel based mechanical kinetic energy recovery systems permits regenerative braking, engine buffering and torque assistance for engine downsizing. These features dramatically improve fuel efficiency and hence reduce fuel consumption and $\mathrm{CO}_{2}$ emissions of vehicles covering driving cycles characterized by accelerations and decelerations.

The engine may be stopped after the flywheel has been charged in a deceleration up to the time the energy stored in the flywheel has been fully consumed. The internal combustion engine energy supply is therefore replaced by the release of the recovered braking energy otherwise lost.

A full size passenger car equipped with a 4 litre, in-line six, throttle controlled, port fuel injected, stoichiometric gasoline engine may have a $25 \%$ better fuel economy over the new European driving cycle (NEDC) without downsizing and a 33\% better fuel economy with an engine downsized to 3.3 litres. Benefits of KERS may vary with vehicle and engine characteristics and will differ on different driving cycles.

The KERS have major areas of development in power density, life, simplicity, effectiveness and first and foremost the costs of the device. Applications are being considered for small, mass-production passenger cars, as well as luxury cars, buses and trucks.

\section{REFERENCES}

1. Ryoji Kasama, Shotaro Naito, Hiroshi Katada, Takanori Shibata, "The Efficiency Improvement of Electric Vehicles By Regenerative Braking”, SAE P. 780291.

2. Simon Slutsky, Enrico Levi, "Regenerative Braking in Diesel-Powered Urban Buses", SAE P. 841690.

3. Floyd A. Wyczalek, Tsih C. Wang, "Regenerative Braking Concepts for Electric Vehicles--A Primer", SAE P. 920648.

4. Floyd A. Wyczalek, Tsih C. Wang, "Electric Vehicle Regenerative Braking", SAE P. 929139.

5. Christian Albrichsfeld, Juergen Karner, "Regenerative Brake System for Hybrid and Electric Vehicles", SAE P. 2009-01-1217.

6. Gino Sovran, Dwight A. Blaser, "Quantifying the Potential Impacts of Regenerative Braking on a Vehicle's Tractive-Fuel Consumption for the U.S., European, and Japanese Driving Schedules”, SAE P. 2006-01-0664. 
7. Michael Panagiotidis, George J. Delagrammatikas, Dennis N. Assanis, "Development and Use of a Regenerative Braking Model for a Parallel Hybrid Electric Vehicle”, SAE P. 2000-01-0995.

8. Wittmer C., Dietrich P., Guzzella L., Control Strategies for the ETH-Hybrid III Vehicle, 1995, Proceedings First IFAC Workshop on Advances in Automotive Control.

9. Wittmer C., Guzzella L., Dietrich P., Optimized Control Strategies for a Hybrid Car with a Heavy Flywheel, 1996, Automatisierungstechnik, Vol. 7, pp. 331-337.

10. Guzzella L., Wittmer Ch., Ender M., Optimal Operation of Drivetrains with SI-Engines and Fly-Wheels, 1996, Proceedings of the 13th IFAC World Congress.

11. B. Vroemen, A. Serrarens, F. Veldpaus, Hierarchical control of the Zero Inertia power train, JSAE, $22(4), 2001$.

12. Brockbank, C., “Application of a variable drive to supercharger and turbo compunder applications”, SAE P. 2009-01-1465.

13. Brockbank, C., and Cross, D., "Mechanical hybrid system comprising a flywheel and CVT for motorsport and mainstream automotive applications”, SAE P. 2009-01-1312.

14. Brockbank, C., and Greenwood, C., "Fuel Economy Benefits of a Flywheel \& CVT Based Mechanical Hybrid for City Bus and Commercial Vehicle Applications", SAE P. 2009-01-2868.

15. Alberto Boretti, "Comparison of fuel economies of high efficiency diesel and hydrogen engines powering a compact car with a flywheel based kinetic energy recovery systems", International Journal of Hydrogen Energy (2010), doi:/10.1016/j.ijhydene.2010.05.031.

16. Diego-Ayala, U., Martinez-Gonzalez, P., McGlashan, N. and Pullen, K., " The mechanical hybrid vehicle: an investigation of a flywheel-based vehicular regenerative energy capture system", Proc. IMechE Vol. 222 Part D: J. Automobile Engineering, pp. 2087-2101, 2008. doi: 10.1243/09544070jauto677.

17. http://www.vcacarfueldata.org.uk (retrieved July 21, 2010).

18. http://ricardo.com/Software/Products/WAVE/ (retrieved July 21, 2010).

19. http://www.lesoft.co.uk/index1.html (retrieved July 21, 2010). 